E-ISSN: 2528-2476

\title{
IMPLEMENTASI KURIKULUM ISMUBA DI MI UNGGULAN MUHAMMADIYAH LEMAHDADI
}

\author{
Fera Eka Widayanti \\ feraeka163@gmail.com \\ Universitas Ahmad Dahlan Yogyakarta \\ Jl. Kapas No.9, Semaki, Umbulharjo, Kota Yogyakarta
}

\begin{abstract}
This research examines the implementation of the Ismuba curriculum at MIU Muhammadiyah Lemahdadi. The research method used is descriptive qualitative, which describes various conditions found in the field about various things related to the implementation of learning Islamic religious education at MIU Muhammadiyah Lemahdadi. The data source consisted of Ismuba subject matter teachers, and a number of other subject teachers as well as homeroom and madrasa principals. Based on the results of the study it can be concluded that the implementation of the Islamic curriculum in the education unit of MIU Muhammadiyah is weak and has been done well. The general subjects have been adjusted to the education office, while the Ismuba curriculum has been adapted to the Muhammadiyah Dikdasmen which is synergized with the madrasah ibtidaiyah curriculum from the ministry of religion. The shortcomings of the implementation of the Islamic curriculum in the education unit of MIU Muhammadiyah Lemahdadi, namely; (1) there is still a lack of teachers' understanding of the sorting of subjects recommended by education and education with the ministry of religion. (2) the allocation of lesson time distribution has not been stable
\end{abstract}

Keywords: Curriculum,Implementation, Ismuba

\begin{abstract}
Abstrak
Penelitian ini memaparkan tentang implementasi pelaksanaan kurikulum Ismuba dalam satuan pendidikan MI. Metode penelitian yang digunakan yaitu deskriptif kualitatif, yaitu memaparkan berbagai kondisi yang ditemukan dilapangan tentang berbagai hal yang berkaitan dengan pelaksanaan pembelajaran pendidikan agama Islam di MI Unggulan Muhammadiyah Lemahdadi. Sumber data terdiri dari guru pengampu mata pelajaran Ismuba, dan sejumlah guru mata pelajaran lainnya serta wali kelas dan kepala madrasah. Berdasarkan hasil penelitian dapat disimpulkan bahwa pelaksanaan kurikulum ismuba di satuan pendidikan MI Unggulan Muhammadiyah lemahdadi sudah dilakukan dengan baik. Mata pelajaran umun telah disesuaikan dengan dinas pendidikan, sedangkan kurikulum Ismuba telah disesuaikan dengan Dikdasmen Muhammadiyah yang di sinergikan dengan kurikulum madrasah ibtidaiyah dari kementrian agama. Adapun kekurangan dari implementasi kurikulum ismuba di satuan pendidikan MIU Muhammadiyah Lemahdadi, yaitu; (1) masih kurangnya pemahaman guru terhadap pemilahan mata pelajaran yang dianjurkan dikdasmen dengan kementrian agama. (2) alokasi waktu pembagian jam pelajaran belum stabil.
\end{abstract}

Kata Kunci: Implementasi, Kurikulum, Ismuba 


\section{PENDAHULUAN}

Dalam dunia pendidikan kurikulum bukanlah kata yang asing, pendidikan atau pembelajaran tidak lepas dari istilah ini, karena kurikulum adalah salah satu komponen dari pembelajaran (Mardiana and Sumiyatun 2017). Kurikulum 2013 mendefinisikan standar kompetensi lulusan (SKL) sesuai dengan yang seharusnya, yakni sebagai kriteria mengenai kualifikasi kemampuan lulusan yang mencakup sikap, pengetahuan dan keterampilan (Kurniaman and Noviana 2019).

Undang-Undang Nomor 20 Tahun 2003 tentang Sistem Pendidikan Nasional menyebutkan bahwa kurikulum adalah seperangkat rencana dan pengaturan mengenai tujuan, isi, dan bahan pelajaran serta cara yang digunakan sebagai pedoman penyelenggaraan kegiatan pembelajaran untuk mencapai tujuan pendidikan tertentu. Berdasarkan pengertian tersebut, ada dua dimensi kurikulum, yang pertama adalah rencana dan pengaturan mengenai tujuan, isi, dan bahan pelajaran, sedangkan yang kedua adalah cara yang digunakan untuk kegiatan pembelajaran (Kemendikbud 2013, 6). Pendidikan agama islam merupakan salah satu materi pembelajaran di lingkungan pendidikan Indonesia dan pada saat ini semakin menjadi perhatian oleh para praktisi pendidikan. Hal ini sangatlah wajar karena pendidikan agama islam mencakup pada penanaman nilai keislaman, akidah syariat dan akhlak sehingga dengan adanya pendidikan agama islam peserta didik akan membawa pampak niali keislaman dalam kehidupan di masyarakat (Rofie 2017). Sebagai sub sistem pendidikan nasional, pendidikan agama Islam selalu mengalami pembaharuan seiring dengan perkembangan ilmu pengetahuan dan teknologi. Hal ini mengakibatkan pada perkembangan kurikulumnya baik tujuan, materi, metode maupun evaluasi. (Ayuhana 2015)

Kurikulum Pendidikan Agama Islam (PAI) merupakan seperangkat rencana dan pengaturan mengenai tujuan, isi, bahan, serta cara pembelajaran yang digunakan sebagai pedoman penyelenggaraan kegiatan pembelajaran untuk mencapai tujuan pendidikan. Ia merupakan sekumpulan studi keislaman yang meliputi al-Qur'an Hadits, Aqidah Akhlaq, Fiqih, Tarikh, dan Kebudayaan Islam. Kurikulum PendidikanAgama Islam (PAI) yang juga memiliki kedudukan yang sangat penting untuk membentuk kepribadian seseorang (Nurmadiah 2018). Sama halnya dengan kurikulum mata pelajaran lain, kurikulum Pendidikan Agama Islam di sekolah juga menjadi acuan dalam kegiatan pembelajaran PAI. Kurikulum PAI dicantumkan dalam kesatuan yang 
integral bersama-sama dengan bidang studi lainnya dalam satuan kurikulum untuk sekolah. Setiap guru agama sebagai pelaksana kurikulum PAI diharapkan dapat mempelajari dengan sebaik-baiknya dan kemudian dapat menggunakannya sesuai dengan teknik pengajaran berdasarkan prinsip interaktif dan komunikatif dengan memperhatikan kegiatan murid, akan tetapi harus bertindak sebagai pembimbing dan dapat mengkoordinir lingkungan serta menyediakan fasilitas agar anak belajar sendiri (Nurmadiah 2014).

Setiap kurikulum mempunyai komponen-komponen untuk mendukung berjalannya kurikulum ditingkat satuan pendidikan. Kurikulum sebagai pola penyampaian materi dalam proses pembelajaran yang disusun dan dilaksanakan oleh sluruh elemen dalam pendidikan. Dalam macam-macam organisasi kurikulum ini kita akan memperoleh sedikit gambaran bagaimana seharusnya pola kurikulum yang sebaiknya dilaksanakan dalam lembaga pendidikan dengan tetap mempertimbangkan minat, bakat dan kemampuan siswa yang ada. Dengan pemilihan bentuk organisasi yang tepat akan mempermudah proses pembelajaran dan dengan hasil yang optimal sesuai harapan.

Kurikulum menjadi sangat penting dalam pembinaan pengembangan kurikulum dan berhubungan erat dengan tujuan program pendidikan, karena bentuk kurikulum adalah menentukan bahan pelajaran, urutan dan cara menyajikan bahan pelajaran tersebut kepada peserta didik. Pada intinya kurikulum disusun untuk mempermudah proses pembelajaran dari guru kepada peserta didik agar tujuan dai pembelajaran tercapai dengan baik. Pada pembahasan ini penulis mencoba untuk mencari tahu bagaimana implementasi kurikulum ismuba di MI Unggulan Muhammadiyah Lemahdadi.

Berdasarkan penelitian terdahulu yang dilakukan oleh Fajrin Maulana dengan judul Implementasi Kurikulum AL-Islam dan Kemuhammadiyahan Dalam Meningkatkan Kadar Religiusitas Siswa SMK Muhammdiyah 2 Sragen, menyatakan bahwa kesadaran peserta didik dalam mengamalkan ajaran agama masih rendah. Oleh sebab itu perlu diterapkan pendidikan Al-Islam dan kemuhamadiyahan untuk meningkatkan kadar religiusitas siswa di SMK Muhammadiyah 2 Sragen. Hasil temuan dari penelitian terdahulu menujukkan bahwa implementasi kurikulum Al-Islam dan Kemuhamadiyahan sebagian besar sudah memenuhi standar impementasi kurikulum. 
Adapun perbedaan antara penelitian terdahulu dengan penelitian penulis yaitu penelitian terdahulu fokus pada hasil peningkatan kadar religiusitas siswa melalui penyelenggaraan pendidikan Al-Islam dan Kemuhammadiyahan, sedangkan penelitian penulis hanya fokus pada pelaksanaan kurikulum Al-Islam dan Kemuhammadiyahan di MI Unggulan Muhammadiyah Lemahdadi.(Maulana 2016)

\section{METODE PENELITIAN}

Penelitian ini merupakan penelitian deskriptif kualitatif, yakni memaparkan berbagai kondisi yang ditemukan dilapangan tentang berbagai hal yang berkaitan dengan pelaksanaan pembelajaran pendidikan agama Islam di MI Unggulan Muhammadiyah Lemahdadi. Proses penelitian dan pengumpulan data menggunakan teknik observasi, wawancara dan dokumentasi, dimana observasi dilakukan dengan cara terjun langsung ke MI yang bersangkutan, sedangkan wawancara dilakukan dengan guru pengampu materi Ismuba, dan dokumentasi sebagai dokumen peneliti.

\section{HASIL PENELITIAN DAN PEMBAHASAN}

Berdasarkan kedudukan dan fungsinya, kurikulum adalah sebuah rancangan kegiatan belajar bagi peserta didik yang meliputi, tujuan, bahan ajar, metode, alat, penilaian yang saling berkaitan satu sama lain. Oleh karena itu, dalam implementasinya seorang guru dituntut untuk mampu merencanakan pelaksanaan pembelajaran, melaksanakan proses pembelajaran yang baik, serta menilai dan mengevaluasi hasil kegiatan belajar mengajar. Dengan demikian kurikulum mempunyai kedudukan yang sangat penting dalam dunia pendidikan (Raharjo 2010, 25). Telah diketahui bahwasanya agama dan pendidikan adalah dua hal yang saling berhubungan satu dengan yang lainnya. Melalui agama, manusia diarahkan menjad manusia sesungguhnya sesuai dengan ajaran agama islam, dan proses untuk memenuhi tahap tersebut adalah melalui pendidikan. Diharapkan dengan adanya pendidikan agama islam tersebut akan menjadikan seseorang bertambah keilmuannya.

Pendidikan Agama Islam (PAI) di sekolah muhammadiyah disebut sebagai ISMUBA (Al - Islam, Ke-Muhammadiyahan dan Bahasa Arab) merupakan suatu disiplin ilmu, yang mempunyai karakteristik dan tujuan keilmuan yang berbeda dengan disiplin ilmu lainnya. Pendidikan agama islam bertujuan unuk menumbuhkan dan meningkatkan keimanan peserta didik melalui pemberian dan pemupukan keimanan, 
ketakwaan kepada Allah SWT. Serta akhlak mulia dalam kehidupan sehari-hari, baik bagi diri sendiri, masyarakat, bangsa dan Negara, yang dewasa ini sering disebut dengan pendidikan karakter (Nasih and Kholidah 2009, 7).

Kurikulum MI Unggulan Muhammadiyah Lemahdadi dikembangkan sebagai perwujudan dari kurikulum pendidikan dasar. Kurikulum ini disusun oleh satu tim penyusun yang terdiri atas unsur sekolah dan komite sekolah di bawah koordinasi dan supervisi Dinas Pendidikan Kabupaten Bantul, serta dengan bimbingan nara sumber ahli pendidikan dan pembelajaran dari Tim Pengembang Kurikulum UPT PPD dan Kecamatan Kasihan . Pengembangan kurikulum ini didasarkan pada prinsip-prinsip sebagai berikut:

1. Berpusat pada potensi, perkembangan, kebutuhan, dan kepentingan peserta didik dan lingkungannya;

2. Beragam dan terpadu;

3. Tanggap terhadap perkembangan ilmu pengetahuan, teknologi dan seni;

4. Relevan dengan kebutuhan kehidupan;

5. Menyeluruh dan berkesinambungan;

6. Belajar sepanjang hayat; dan

7. Seimbang antara kepentingan nasional dan kepentingan daerah.

Pengembangan Kurikulum MI Unggulan Muhammadiyah Lemahdadi mengacu pada standar nasional pendidikan yang terdiri atas standar isi, standar proses, standar kompetensi lulusan, tenaga kependidikan, sarana dan prasarana, pengelolaan, pembiayaan, dan penilaian pendidikan. Empat dari kedelapan standar nasional pendidikan tersebut, yaitu Standar Penilaian Lulusan (SKL), Standar Isi, Standar Proses, dan Standar Penilaian merupakan acuan utama bagi satuan pendidikan dalam perancangan dan pengembangan kurikulum MI Unggulan Muhammadiyah Lemahdadi. Hidayati (2014) menyatakan bahwa dalam pengembangan kurikulum perlu memperhatikan beberapa langkah, diantaranya adalah : identifikasi kebutuhan pendidikan, analisa dan pengukuran kebutuhan pendidikan, penyusunan dsain kurikulum.

Andi (Prastowo 2014) memaparkan Pasal 2 Permendikbud No. 81a Tahun 2013 mengatur bahwa implementasi kurikulum pada SD/MI, SMP/MTs, SMA/MA, dan SMK/MAK menggunakan pedoman implementasi kurikulum yang mencakup : pertama, 
Pedoman Penyusunan dan Pengelolaan Kurikulum Tingkat Satuan Pendidikan ; kedua, Pedoman Pengembangan Muatan Lokal;ketiga, Pedoman Kegiatan Ekstrakurikuler; keempat, Pedoman Umum Pembelajaran; dan kelima, Pedoman Evaluasi Kurikulum. Dengan kata lain, proses implementasi kurikulum 2013 di Madrasah Ibtidaiyah juga tidak begitu berbeda dengan proses implementasi yang berlangsung di Sekolah Dasar, yakni merujuk pedoman implementasi yang dikembangkan oleh Kemendikbud tersebut, meskipun pada beberapa aspek dilakukan penyesuaian, seperti di antaranya pada aspek standar isi mata pelajaran Pendidikan Agama Islam, mata pelajaran Bahasa Arab dan pengadaan buku ajar serta buku pegangan bagi guru.

Pendidikan Agama Islam di Madrasah (Ibtidaiyah) berbeda dengan sekolah umum. Khusus untuk proses penyusunan buku, Kementerian Agama mengerjakannya sendiri dengan disesuaikan semangat Kurikulum 2013 dan menggunakan pendekatan tematik-integratif. Sedangkan buku wajib bidang studi, Madrasah Ibtidaiyah menggunakan buku-buku yang sudah disiapkan oleh Kemendikbud. Sedangkan pendidikan Agama islam di MIU Muhammadiyah lemahdadi mengkolaborasikan antara kurikulum SD, dan Kurikulum Madrasah, agar keduanya saling terintegrasi. Oleh karena itu dengan kondisi yang seperti ini organisasi kurikulum memiliki peran yang sangat penting dalam perumusan kurikulum di MIU Muhammadiyah Lemahdadi, karena di dalamnya terdapat pembahasan mengenai desain pembelajaran peserta didik pada satuan pendidikan. Dalam buku karya Teguh Triwiyanto (2015 : 152) disebutkan bahwa terdapat tiga aspek yang harus diperhatikan dalam pengorganisasian kurikulum, diantaranya adalah sebagai berikut :

1. Merinci materi pelajaran, menentukan beban dan jenis materi pelajaran untuk mencapai tujuan pendidikan.

2. Pembagian materi pelajaran sesuai dengan jenjang pendidikan pada satuan pendidikan.

3. Pengembangan mekanisme hubungan antara materi pelajaran berdasarkan jenjang pendidikan.

Sedangkan prinsip yang perlu diperhatikan dalam organisasi kurikulum antara lain ruang lingkup, urutan bahan, kontinuitas, keseimbangan dan keterpaduan. Ruang lingkup dan urutan bahan pelajaran menjadi pertimbangan yang sangat penting karena setiap pola kurikulum memiliki cakupan materi pelajaran yang berbeda. Selain itu yang 
juga perlu diperhatikan adalah urutan materi pelajaran yang nantinya disajikan dalam kurikulum. Kontinuitas berkaitan dengan isi bahan pelajaran atau materi yang akan disajikan kepada peserta didik. jangan sampai dalam penyajian materi, isi materi menjadi tidak teratur, misalnya materi yang tidak perlu disajikan tetap tersaji, atau terjadi pengulangan materi. Sehingga dikhawatirkan peserta didik tidak bisa focus pada materi. Ada dua aspek dalam keseimbangan organisasi kurikulum, pertama keseimbangan isi kurikulum, hal ini harus dilihat secara luas untuk kepentingan peserta didik sebagai individu dan tuntutan masyarakat; kedua keseimbangan proses belajar. (MKDP, 2011:88)

Berdasarkan hasil wawancara dengan guru pengampu PAI di MI Unggulan Muhammadiyah Lemahdadi, menunjukkan bahwa madrasah tersebut telah menggunakan kurikulum PAI madrasah yang dipadukan dengan kurikulum ismuba dari dikdasmen muhammadiyah. Meskipun demikian ada beberapa kendala dalam penerapan organisasi kurikulum tersebut, diantaranya adalah memilah-milah mata pelajaran agama apa saja yang diambil dari kemenag dan dikdasmen, terutama untuk mata pelajaran fikih ibadah. Karena dalam mata pelajaran tersebut ada beberapa materi yang berbeda. Sedangkan Kurikulum ismuba di MI U Muh lemahdadi tetap digunakan untuk mata pelajaran ke-muhammadiyahan dan fikih ibadah. Selebihnya menggunakan kurikulum dari kemenag.

Implementasi kurikulum ismuba di MI Unggulan Muhammadiyah Lemahdadi sudah diterapkan dengan cukup baik yang mengacu pada dua pendekatan pengorganisasian kurikulum, yaitu pendekatan secara structural atau manajemen dan pendekatan secara fungsional atau akademik. Pada kedua pendekatan tersebut saling memiliki keterkaitan satu sama lainnya dan berjalan beriringan selama proses pelaksanaannya. Pendekatan organisasi kurikulum secara manajemen antara lain:

a. Organisasi perencanan kurikulum, organisasi perencanaan ini dilakukan oleh tim atau kelompok pengembang kurikulum atau lembaga yang mengembangkan kurikulum.

b. Organisasi dalam rangka pelaksanaan kurikulum, pada bagian ini, dilakukan oleh pihak lembaga daerah atau tingkat satuan pendidikan yang sedang melaksanakan pengembangan kurikulum. 
c. Organisasi dalam evaluasi kurikulum, dilaksanakan oleh lembaga atau satuan pendidikan dan melibatkan berbagai pihak dalam pelaksanaannya.

Pada masing-masing pendekatan tersebut akan dilakukan oleh seseorang sesuai dengan tugas yang telah ditentukan dalam struktural organisasi kurikulum. Pendekatan secara akademik, organisasi kurikulum dikembangkan dalam bentuk model atau pola organisasi sebagai berikut:

a. Kurikulum mata pelajaran, yang terdiri dari beberapa mata pelajaran yang terpisah-pisah.

b. Kurikulum bidang studi, yaitu menghubungkan beberapa mata pelajaran menjadi satu kesatuan.

c. Kurikulum integrasi, yang menyatukan beberapa kurikulum atau masalah sehingga memiliki topic masalah tersendiri dan biasanya diselesaikan melalui problem solving.

d. Core curriculum, yakni kurikulum yang disusun berdasarkan masalah kebutuhan peserta didik. (Hamalik, 2017 : 136)

Mulyasa (Mulyasa 2013) menjelaskan ada beberapa kunci sukses agar impelementasi Kurikulum 2013 berjalan dengan sukses yaitu ;

a. kepemimpinan kepala sekolah.

b. kretifitas guru.

c. Aktifitas peserta didik.

d. Sosialisasi Kurikulum 2013

e. Fasilitas dan sumber belajar.

f. Lingkungan yang kondusif akademik.

g. Partisipasi warga sekolah.

Merujuk pada jurnal (Wibowo 2010) bahwa penyusunan kurikulum yang baik adalah dapat mengaplikasikan kurikulum secara rinci. MI Muh. Lemahdadi dalam implementasinya sudah dapat dikatakan cukup baik, namun dalam penyusunan RPP terkadang apa yang disusun akan berbeda dengan yang disampaikan kepada peserta didiknya. Hal ini masih sering terjadi dikarenakan guru harus berulang kali mengkondisikan peserta didik agar tetap mengikuti proses pembelajaran dengan baik sehingga apa yang disampaikan tidak sesuai dengan RPP. Namun tidaklah menjadi masalah selama materi yang disampaikan tidak terbengkalai. Berikut adalah sruktur dan 
Muatan Kurikulum pada jenjang pendidikan dasar dan menengah meliputi lima kelompok mata pelajaran yaitu:

1. Kelompok mata pelajaran agama dan akhlak mulia.

2. Kelompok mata pelajaran kewarganegaraan dan kepribadian.

3. Kelompok mata pelajaran ilmu pengetahuan dan teknologi.

4. Kelompok mata pelajaran estetika.

5. Kelompok mata pelajaran pendidikan jasmani, olah raga, dan kesehatan.

Cakupan tiap kelompok mata pelajaran untuk SD/MI/SDLB disajikan seperti tabel berikut:

Tabel 1.1 Cakupan Tiap Kelompok Mata Pelajaran

\begin{tabular}{|c|c|l|}
\hline $\begin{array}{c}\text { N } \\
\text { o }\end{array}$ & $\begin{array}{c}\text { Kelompok Mata } \\
\text { Pelajaran }\end{array}$ & \multicolumn{1}{|c|}{ Cakupan } \\
\hline 1 & $(2)$ & \multicolumn{1}{|c|}{$(3)$} \\
\hline 1 & $\begin{array}{l}\text { Agama dan Akhlak } \\
\text { Mulia }\end{array}$ & $\begin{array}{l}\text { Kelompok pelajaran agama dan akhlak mulia } \\
\text { dimaksudkan untuk membentuk peserta didik menjadi } \\
\text { manusia tang beriman dan bertaqwa kepada Tuhan Yang } \\
\text { Maha Esa serta berakhlak mulia mencakup etika, budi } \\
\text { pekerti atau moral sebagai perwujudan dan pendidikan } \\
\text { agama. }\end{array}$ \\
\hline 2 & $\begin{array}{l}\text { Kewarganegaraan } \\
\text { dan Kepribadian }\end{array}$ & $\begin{array}{l}\text { Kelompok mata pelajaran kewarganegaraan dan } \\
\text { kepribadian dimaksudkan untuk meningkatkan kesadaran } \\
\text { dan wawasan peserta didik akan ststus, hak dan } \\
\text { kewajibannya dalam kehidupan bermasyarakat dan } \\
\text { bernegara serta peningkatan kualitas dirinya sebagai } \\
\text { manusia, kesadaran dan wawasan, termasuk wawasan } \\
\text { kebangsaan, jiwa patriotisme bela negara, penghargaan } \\
\text { terhadap hak-hak asasi manusia kemajemukan bangsa, } \\
\text { pelestarian lingungan hidup, kesetaraan jender demokrasi, } \\
\text { tanggung jawab social, ketaatan pada hukum, ketaatan } \\
\text { membayar pajak dan sikap atau perilaku, anti korupsi, } \\
\text { kolusi dan nepotisme. }\end{array}$ \\
\hline
\end{tabular}




\begin{tabular}{|c|c|c|}
\hline 3 & $\begin{array}{l}\text { Ilmu pengetahuan } \\
\text { dan Teknologi }\end{array}$ & $\begin{array}{l}\text { Kelompok mata pelajaran ilmu pengetahuan dan } \\
\text { tekmologi pada SD/MI/SDLB/Paket A dimaksudkan } \\
\text { untuk mengenal menyikapi dan mengapresiasi ilmu } \\
\text { pengetahuan dan teknologi serta menenemkan kebiasaan } \\
\text { berfikir dan berperilaku ilmiah yang kritis kreatif dan } \\
\text { mandiri. }\end{array}$ \\
\hline 4 & Estetika & $\begin{array}{l}\text { Kelompok pelajaran estetika dimaksudkan untuk } \\
\text { meningkatkan sensitivitas, kemampuan mengapresiasi } \\
\text { keindahan serta harmoni mencakup apresiasi dan } \\
\text { ekspresi, baik dalam kehidupan individual sehingga } \\
\text { mampu menikmati an mensyukuri hidup maupun dalam } \\
\text { kehidupan kemasyarakatan sehingga mampu menciptakan } \\
\text { kebersamaan yang harmonis. }\end{array}$ \\
\hline 5 & $\begin{array}{l}\text { Jasmani, Olahraga } \\
\text { dan Kesehatan }\end{array}$ & $\begin{array}{l}\text { Kelompok mata pelajaran jasmani, olahraga dan } \\
\text { kesehatan pada SD/MI/SDLB/paket A dimaksudkan } \\
\text { untuk meningkatkan potensi fisik serta menanamkan } \\
\text { sportifitas dan kesadaran hidup sehat.Budaya hidup sehat } \\
\text { termasuk kesadaran msikap dan perilaku hidup sehat } \\
\text { yang bersifat individual ataupun yang bersifat } \\
\text { kemasyarakatan seperti keterbatasan dari perilaku } \\
\text { seksual bebas, kecanduan narkoba, NIV/AIDS, demam } \\
\text { berdarah, Muntaber dan penyakit lain yang potensial } \\
\text { untuk mewabah. }\end{array}$ \\
\hline
\end{tabular}

Selanjutnya dalam pasal 7 Peraturan Pemerinyah Nomor 19 Tahun 2005 Tentang Standar Nasional Pendidikan dijelaskan pula bahwa:

1. Kelompok mata pelajaran agama dan akhlak mulia mulai pada SD/MI/SDLB/Paket A, dilaksanakan melalui muatan dan atau kegiatan agama, kewarganegaraan, kepribadian, ilmu pengetahuan dan teknologi, estetika, jasmani, olahraga dan kesehatan. 
2. Kelompok mata pelajaran kewarganegaraan dan kepribadian pada SD/MI/SDLB/Paket A dilaksanakan melalui dan atau kegiatan agama, kewarganegaraan, bahasa, seni dan budaya, dan pendidikan jasmani

3. Kelompok mata pelajaran ilmu pengetahuan dan teknologi pada SD/MI/SDLB/Paket A, dilaksanakan melalui muatan dan atau kegiatan bahasa.matematika, ilmu pengetahuan alam,ilmu pengetahuan social keterampilan/ kejuruan, dan muatan lokal yang relevan.

4. Kelompok pelajaran estetika pada SD/MI/SDLB/Paket A dilaksanakan melalui muatan dan atau kegiatan bahasa,seni dan budaya,keterampilan / kejuruan dan muatan lokal yang relevan

5. Kelompok mata pelajaran jasmani,olahraga dan kesehatan pada SD/MI/SDLB/Paket A, dilaksanakan melalui muatan dan atau kegiatan pendidikan jasmani, pendidikan kesehatan,ilmu pengetahuan alam dan muatan lokal yang relevan.

Kelompok mata pelajaran Kurikulum 2013 untuk kelas I, II, III, IV dan V dan VI disajikan seperti tabel berikut:

Tabel 1.2 Kelompok Mata Pelajaran Kurikulum 2013

\begin{tabular}{|c|l|}
\hline \multicolumn{2}{|c|}{ MATAPELAJARAN } \\
\hline \multicolumn{2}{|c|}{ Mata Pelajaran } \\
\hline 1. & Alquran Hadits \\
\hline 2. & Aqidah Akhlak \\
\hline 3. & Sejarah Kebudayaan Islam \\
\hline 4. & Fiqih \\
\hline 5. & B. Arab \\
\hline 6. & Kemuhammadiyahan \\
\hline 7. & Tematik \\
\hline 8. & Matematika \\
\hline 9. & PJOK \\
\hline B. Muatan Lokal & \\
\hline 1. & Bahasa Jawa \\
\hline 2. & Bahasa Inggris \\
\hline
\end{tabular}




\begin{tabular}{|c|c|}
\hline 3. & Tahfidz \\
\hline C. Pengembangan Diri \\
\hline 1. & Hizbul Wathon \\
\hline 2. & TPA \\
\hline 3. & Tapak Suci \\
\hline
\end{tabular}

Struktur Kurikulum MI Unggulan Muhammadiyah Lemahdadi disusun berdasarkan standar kompetensi lulusan dan kompetensi mata pelajaran dengan ketentuan sebagai berikut:

1. Kurikulum MI Unggulan Muhammadiyah Lemahdadi memuat 8 mata pelajaran, muatan lokal SD dan pengembangan diri seperti tertera pada tabel 1.3.

2. Pembelajaran pada kelas I-V dilaksanakan melalui pendekatan tematik/tematik terpadu, sedangkan kelas VI dilaksanakan melalui pendekatan mata pelajaran.

3. Jumlah jam pembelajaran untuk setiap mata pelajaran dialokasikan sebagaimana tertera dalam struktur kurikulum MI Unggulan Muhammadiyah Lemahdadi dan menambah 4 jam pembelajaran per minggu untuk kelas I - VI menambah 2 jam pelajaran.

4. Alokasi waktu satu jam pembelajaran adalah 30 menit.

5. Minggu efektif dalam satu tahun pelajaran adalah 37 minggu.

Adapun muatan Kurikulum MI Unggulan Muhammadiyah Lemahdadi seperti ketentuan tersebut tersusun dalam tabeL berikut:

1. Muatan Kurikulum MI Unggulan Muhammadiyah Lemahdadi

\begin{tabular}{|c|c|c|c|c|c|c|c|}
\hline \multirow{2}{*}{\multicolumn{2}{|c|}{ MATAPELAJARAN }} & \multicolumn{6}{|c|}{$\begin{array}{c}\text { ALOKASI WAKTU PER } \\
\text { MINGGU }\end{array}$} \\
\hline & & I & II & III & IV & $\mathbf{V}$ & VI \\
\hline \multicolumn{8}{|c|}{ D. Mata Pelajaran } \\
\hline 1. & Alquran Hadits & 2 & 2 & 2 & 2 & 2 & 2 \\
\hline 2. & Aqidah Akhlak & 2 & 2 & 2 & 2 & 2 & 2 \\
\hline 3. & Sejarah Kebudayaan Islam & 1 & 1 & 1 & 1 & 1 & 1 \\
\hline
\end{tabular}


E-ISSN: 2528-2476

\begin{tabular}{|c|c|c|c|c|c|c|c|}
\hline 4. & Fiqih & 2 & 2 & 2 & 2 & 2 & 2 \\
\hline 5. & B. Arab & 2 & 2 & 2 & 2 & 2 & 2 \\
\hline 6. & Kemuhammadiyahan & - & - & 1 & 1 & 1 & 1 \\
\hline 7. & Tematik & 20 & 20 & 20 & 16 & 16 & 16 \\
\hline 8. & Matematika & - & - & - & 4 & 4 & 4 \\
\hline 9. & PJOK & 3 & 3 & 3 & 3 & 3 & 3 \\
\hline \multicolumn{8}{|c|}{ E. Muatan Lokal } \\
\hline 1. & Bahasa Jawa & 2 & 2 & 2 & 2 & 2 & 2 \\
\hline 2. & Bahasa Inggris & 2 & 2 & 2 & 2 & 2 & 2 \\
\hline 3 & Tahfidz & 1 & 1 & 1 & 1 & 1 & 1 \\
\hline \multicolumn{8}{|c|}{ F. Pengembangan Diri } \\
\hline 1. & Hizbul Wathon & - & - & 2 & 2 & 2 & 2 \\
\hline 2. & TPA & 2 & 2 & 2 & 2 & 2 & 2 \\
\hline 3. & Tapak Suci & - & - & 2 & 2 & 2 & 2 \\
\hline \multicolumn{2}{|r|}{ Jumlah Alokasi Waktu Per Minggu } & 39 & 39 & 42 & 44 & 44 & 44 \\
\hline
\end{tabular}

Table 1.3 Struktur Kurikulum MI Unggulan Muhammadiyah Lemahdadi

\section{SIMPULAN DAN SARAN}

Berdasarkan hasil penelitian dapat disimpulkan bahwa pelaksanaan kurikulum ismuba di satuan pendidikan MI Unggulan Muhammadiyah lemahdadi sudah dilakukan dengan baik. Pembagian mata pelajaran telah dilakukan dengan mengacu pada standar pendidikan satuan SD/MI. Mata pelajaran umun telah disesuaikan dengan dinas pendidikan, sedangkan kurikulum Ismuba telah disesuaikan dengan Dikdasmen Muhammadiyah yang di sinergikan dengan kurikulum madrasah ibtidaiyah dari kementrian agama. Sama halnya dengan jam belajar yang telah disesuaikan pula dengan dinas pendidikan, dikdasmen dan kementrian agama.

Adapun kekurangan dari implementasi kurikulum ismuba di satuan pendidikan MIU Muhammadiyah Lemahdadi, yaitu; (1) masih kurangnya pemahaman guru terhadap pemilahan mata pelajaran yang dianjurkan dikdasmen dengan kementrian agama. (2) alokasi waktu pembagian jam pelajaran belum stabil.

Adapun saran yang dapat penulis sampaikan dalam penulisan ini ialah implementasi kurikulum ISMUBA agar tetap dilaksanakan di MI unggulan 
Muhammadiyah karena dari penerapan kurikulum tersebut dapat meningkatkan mutu Pendidikan Agama Islam.

\section{DAFTAR PUSTAKA}

Ayuhana, Maherlina Muna. 2015. "Perkembangan Kurikulum Pendidikan Agama Islam Sekolah Dasar Di Indonesia.” Jurnal Tarbawi 12 (2): 171.

Hamalik, Oemar. 2017. Manajemen Pengembangan Kurikulum. Bandung: Bandung : Remaja Rosdakarya.

Hidayati, Lili. 2014. "Kurikulum 2013 Dan Arah Baru Pendidikan Agama Islam." Insania 19 (1): 60-86.

Kemendikbud. 2013. Pedoman Pelatihan Implementasi Kurikulum 2013 Ke-1. Jakarta: Pengembangan SDM Pendidikan dan Kebudayaan dan Penjamina Mutu Pendidikan.

Kurniaman, Otang, and Eddy Noviana. 2019. "Penerapan Kurikulum 2013 Dalam Meningkatkan Keterampilan, Sikap, Dan Pengetahuan.” Primary: Jurnal Pendidikan Guru Sekolah Dasar 6 (2): 390. https://doi.org/10.33578/jpfkip.v6i2.4520.

Mardiana, Safitri, and Sumiyatun Sumiyatun. 2017. "Implementasi Kurikulum 2013 Dalam Pembelajaran Sejarah Di Sma Negeri 1 Metro." Historia 5 (1): 46. https://doi.org/10.24127/hj.v5i1.732.

Maulana, Fajrin. 2016. "Implementasi Kurikulum Al-Islam Dan Kemuhammadiyahan Dalam Meningkatkan Kadar Religiusitas Siswa SMK Muhammadiyah 2 Sragen."

MKDP, tim pengembang. 2011. Kurikulum Dan Pembelajaran. Jakarta: Jakarta : Raja Grafindo Persada.

Mulyasa, E. 2013. Pengembangan Dan Penerapan Kurikulum 213. Bandung : Remaja Rosdakarya.

Nasih, Ahmad Munjin, and Lilik Nur Kholidah. 2009. Metode Dan Teknik Pembelajaran Agama Islam. Bandung : PT. Refika Aditama.

Nurmadiah. 2014. "Kurikulum Pendidikan Agama Islam.” Al-Afkar III (II).

Nurmadiah, Nurmadiah. 2018. "Kurikulum Pendidikan Agama Islam." Al-Afkar : Jurnal Keislaman \& Peradaban 2 (2): 42. https://doi.org/10.28944/afkar.v2i2.93.

Prastowo, Andi. 2014. "Paradigma Baru Madrasah Dalam Implementasi Kebijakan Kurikulum 2013." Jurnal Pendidikan Islam IIII (1): 95-114. https://doi.org/10.14421/jpi.2014.31.95-113.

Raharjo, Rahmat. 2010. Inovasi Kurikulum Pendidikan Agama Islam Pengembangan Kurikulum Dan Pembelajaran. Yogyakarta : Magnum Pustaka.

Rofie, Moh. 2017. "Manajemen Kurikulum Pendidikan Agama Islam Berbasis Pesantren (Studi Kasus Di Tarbiyatul Muallimien Al-Islamiyah Al-Amien Prenduan)." Jurnal Reflektika 12 (2): 149-69.

Teguh Triwiyanto. 2015. Manajemen Kurikulum Dan Pembelajaran. Jakarta: Jakarta : Bumi Aksara.

Wibowo, A.M. 2010. "Dampak Kurikulum PAI Terhadap Perilaku Keagamaan (Studi Komparasi Antara Kurikulum PAI Plus Dengan PAI Diknas)." Analisa XVII (01): 117-30. 